\title{
Dynamics of Climatic Factors: Implications on Household Food Security in the Jirapa Municipal of The Upper West Region, Ghana
}

\author{
Paul Alhassan Zaato ${ }^{1,2 *}$ Nicholas Yembillah ${ }^{1}$ Victor Afari-Sefa ${ }^{3}$ Sylvester Sungbaahee ${ }^{2}$ \\ 1. Department of Environment and Resource Studies, University for Development Studies, Wa, Ghana \\ 2. West and Central Africa - Coastal and Humid Region, World Vegetable Center, Tamale Station, Ghana \\ 3. West and Central Africa - Coastal and Humid Region, World Vegetable Center, Cotonou Station, Benin \\ *Correspondence E-mail: paul.zaato@worldveg.org
}

\begin{abstract}
The study assessed the implications that climatic factors has on the food security of rural household within the Jirapa municipality. The perception of 180 rural farm households on climate change was analyzed using a quantitative approach. The study also examined some climate variables using time series data from the Ghana Meteorological Authority for a period of 57 years. Pattern examination of precipitation and temperature were done using Simple Linear Regression (SLR) and Standardized Precipitation Index (SPI) over the 57 year interval. The results showed that, most of the individual respondents $(69.5 \%)$ experienced a rise in temperature over the past years and a decline in rainfall (65\%). Data from the Ghana Meteorological Authority (GMA) showed an increasing trend for temperature $\left(1.28^{\circ} \mathrm{C}\right)$ over the 57 year period and $0.224^{\circ} \mathrm{C}$ rise per decade with a decline in rainfall and eratic rainfall distribution over the past 57 years. The presence of climatic extremes had serious implications for food availability, stability, accessibility and utilization. It is recommended that policy and development measures should therefore concentrate on promoting the resilience and adaptive capacity of rural households towards climate change to promote food security.
\end{abstract}

Keywords: Climate change, Food Security, Livelihood, Agricultural Productivity, Ghana

DOI: $10.7176 / \mathrm{JESD} / 13-4-04$

Publication date: February $28^{\text {th }} 2022$

\section{Introduction}

Climate change is a slow alternation in weather condition over an extended length of time, that is attributed to anthropogenic activities (UNFCC, 2011). Its influences are extensively found in the African continent, where it has impacted climate dependent activities, social aspects which include education and health (Lawson et al., 2020). The African continent is highly susceptible to the consequences of climate change because of Africa's low level adaptive capability and climate reliant agriculture (Tirado et al., 2010; IPCC, 2012).

A great number of Ghanaians livelihoods are sustained through agriculture productivity with $80 \%$ of local production emanating from smallholder farmers (Naab et al., 2019). Agriculture related activities provides employment to about $60 \%$ of the working class in Ghana and the sector is mostly dominated by small-scale farmers (MOFA, 2016). Severe floods and droughts are the main weather related extreme events that pose serious risk to agricultural productivity in Ghana (IFAD, 2012). Between 1960 and 2000, the Ghana Meteorological Agency noted an increase in temperature and rainfall variability all around the country. Based on those facts available, climate stimulations revealed that, Ghana will experience a $2^{\circ} \mathrm{C}$ rise in temperature by 2050 . Rainfall is likewise anticipated to lower in those regions through a mean of $11 \%$ (UNFCCC, 2009). This will pose a severe negative impact on household food security within Ghana and most especially northern Ghana, in which environmental situations are already characterized by soil erosion, land degradation, deforestation, and lack of water supply (IPCC, 2013).

The northern regions of Ghana are at a high risk in terms of food insecurity because of their constant exposure to excessive temperatures, inadequate rainfall, high poverty rate and poor soil quality. It is difficult for smallholder farmers to plan for the planting season and their predictive local knowledge is challenged due to erratic rainfalls and shifting weather patterns (WFP, 2009). Households in the Upper West Region rely mainly on rainfall for the cultivation of crops. Unfortunately, the rains have become uncertain and cannot be predicted due to climate change and the soil fertility levels are dropping which in addition will aggravate the levels of food insecurity within the region.

The study conducted by Subaar et al. (2018) did not discuss the implications of climatic factors on food security and similar observations were seen in other studies (Peprah, 2014; Asamoah and Mensah, 2020). Akudugu et al. (2012) is among the few that looked into the implications of climatic factors on household food security within Northern Ghana, they did not however do a temporal evaluation on climatic parameters to support their discussion. Our study will therefore provide discussions relating to the implications of climatic variables on food security. Asamoah and Mensah (2020) reported a stability in rainfall distribution for the period of 39 years (1979 
to 2015). This is so because their study period was shorter and not dated back to an earlier time (Owusu and Weylen, 2009; Issahaku et al., 2016;). It was also noted by (Elagib, 2013) that SPI data of longer time scales have been shown to exhibit relatively better performance in describing the drought characteristics in contrast to shorter time scales. Our study will therefore fill this gap by conducting analyses of meteorological data for a period of 57 years (1961-2017) to enable us make a good conclusion on the incidence of climatic variability within the district. Our study is also the first of its kind to conduct time series analysis on metrological data for this extended number of years.

Consequently, our study seeks to close the knowledge gap by discussing the implications of climatic factors on food security. The study also analyses climatic variables using information from the Ghana meteorological Service for a duration of fifty-seven years. Local perception on the incidence of climate change will also be seeked to better recommend local adaptation measures.

\section{Materials and Methods}

2.1 Study Area

The Jirapa Municipality is found within the Upper West Region of Ghana with an average mean temperature between $28^{\circ} \mathrm{C}$ and $31^{\circ} \mathrm{C}$ (Figure.1). Anthropogenic activities such as burning of bush, deforestation, poor farming systems sand winning leads to the destruction of grassland and therefore the environment within the municipality. The topography of the municipal is mainly flat and low and the soil type is sandy loam. The predominant economic activity in the municipality is agriculture with crop production been the major agriculture activity. The people generally practice subsistence agriculture. The major important crops cultivated in the municipality are maize, millet, cotton, groundnuts and cashew (GSS, 2014). We chose the Jirapa municipality for this study primarily because of its reliance on rain-fed subsistence farming, the occurrence of extreme weather conditions and degraded farm lands within the district.

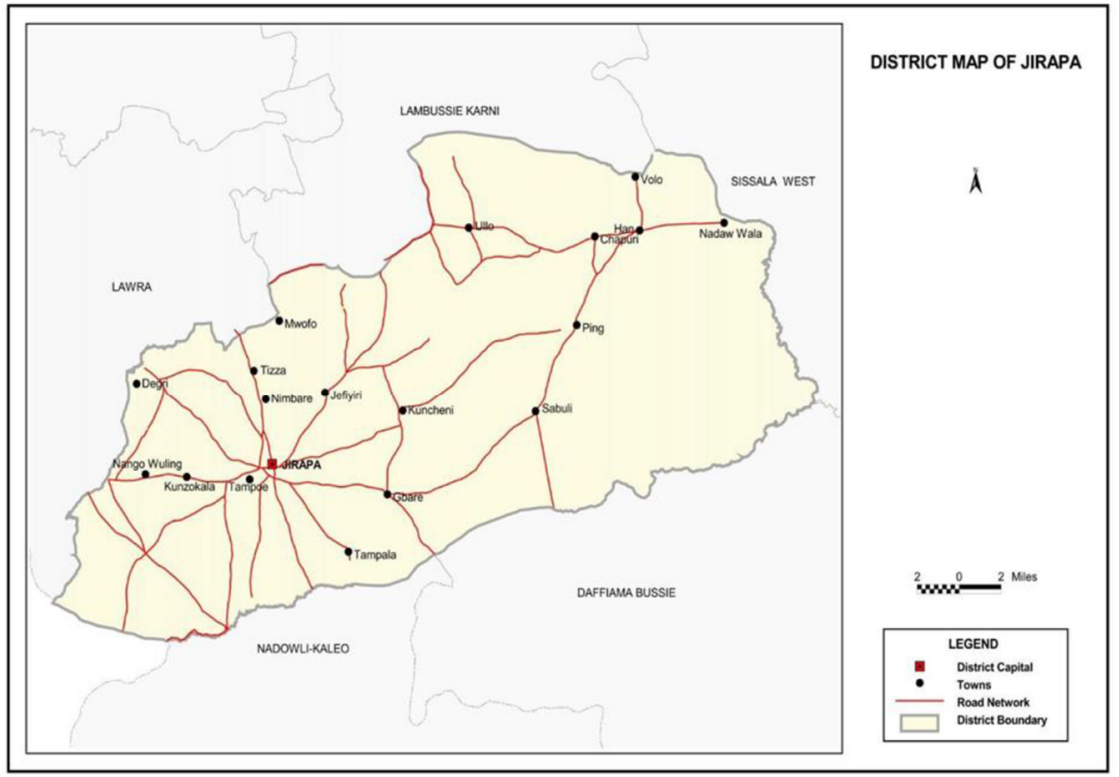

Figure 1. Map of the study area

\subsection{Data collection and Sampling}

The Upper West Region was purposely selected because the regions susceptiveness to climate change and variability has been on the rise and poverty has been highly predominant (Lawson et al, 2019). The study sampled data from 180 rural farm households from five communities within the western belt operational area of the district using multistage stratified random sampling technique. Five communities were randomly selected from the five zones in the Western belt operational area of the district in accordance with the District Agricultural Office zoning. Secondary data from the Ghana Meteorological Service for the past fifty-seven (57) year period was also collected. The sample size for each community was determined using the probability proportional to size (PPS) methodology which presents equivalent likeness of households in each community using Yamane (1967).

Mathematically presented as:

$$
n=\frac{N}{1}+N(e)^{2}
$$


$n=$ Sample size used

$N=$ Sum of households in all the communities (328)

$e=$ Error margin

$5 \%(0.05)$, and $1=$ probability of the event occurring.

The mathematical formula provides a sample size of 180 .

\subsection{Measurement Technique and Empirical Model}

This study used the Likert-scale which provides an ordinal-level measure of respondents' perceptions about situation, events or object, in this case climate change (Newman, 2014). In this study, the respondents were asked to either agree or disagree with variability in rainfall and temperature pattern as experienced previously.

This study adopted a linear regression model to predict the temperature and rainfall variations over the 57-year period. The linear regression model is effectively used in the study of relationships among variables. The model assumes that, there is a linearity of the relationship between dependent and independent variables (temperature and rainfall). The linear regression model is therefore specified as:

$$
Y=X \beta+\varepsilon
$$

$\mathrm{Y}=$ changes in rainfall and temperature; $\beta=$ slope of the regression equation; $\mathrm{X}=$ number of years from 1961 to $2017 ; \varepsilon=$ error term or disturbance term. It thus translates into the equations 3 and 4 :

$$
\text { Temperature }=\beta_{0}+\beta_{i} \text { timeperiod }+\varepsilon \text {. }
$$

$$
\text { Rainf all }=\beta_{0}+\beta_{i} \text { timeperiod }+\varepsilon
$$

\subsection{Standard Precipitation Index (SPI)}

The SPI adopted from (Mckee et al., 1993) was employed to identify drought periods from annual rainfall data within the 57-year period. The SPI statistically measures abnormal weather conditions which makes it easier to ascertain the frequency of drought occurrences. It is calculated as:

$$
S P I=\frac{(x-\vec{x})}{\sigma} .
$$

SPI = Rainfall irregularity: $\mathrm{X}=$ Yearly: $\vec{x}=$ Long-term average rainfall: $\sigma=$ Standard deviation

The duration of drought, its magnitude (DM) and intensity(DI) were computed from quantified values of SPI. Mathematically expressed as:

$$
D M=\sum_{j=1}^{x}-\left(S P I_{i j}\right)
$$

$\mathrm{j}=$ Month/year of a drought

$i=i t h$ month or year from the observation period.

Drought Intensity $(\mathrm{DI})=\frac{M i}{L i}$

$M i=$ drought magnitude: $L i=$ drought duration (Mckee et al., 1993).

\section{Results}

3.1 Socio-demographic and Occupational Characteristics of Respondents

The results indicate that, $89.4 \%$ of the household heads were males. About $59 \%$ of the household heads in the study communities are within the age category of 50 years and above, $38.3 \%$ within $30-49$ years, and $2.7 \%$ were within the age range of $15-29$ years. The average household size was estimated to be 8 . About $74.4 \%$ of the sample had no formal education. About sixteen (16.1\%) of them had primary education, $6.7 \%$ had secondary/middle school education, whiles $2.8 \%$ had secondary education. The majority $(44.4 \%)$ of the farmers were small scale peasant farmers who only farm large enough to feed themselves. They may only sell in case of surplus, with an average farm size of 2 acres, a minimum of 1 acre and a highest of 9 acres.

\subsection{Respondents Perception of Temperature and Rainfall Variations}

About $87 \%$ of the respondents perceived changes in temperature whiles approximately $13 \%$ perceived no changes 
in the temperature pattern over their lifetime [Figure. 2]. $70 \%$ of the respondents perceived an increasing temperature over time, about $23 \%$ perceived an erratic pattern in temperature distribution while about $3 \%$ perceived temperature to be decreasing over time. The perceptions of households on rainfall changes was analyzed according to their observations and environmental experiences. About $89 \%(\mathrm{~N}=160)$ of respondents have perceived changes in rainfall amount whiles $11.1 \%$ of respondents have not perceived any change in rainfall pattern [Figure. 3]. Among individuals who perceived changes in the rainfall pattern, (117) representing 65\% perceived a decline in the amount of rainfall within their respective communities. $21.7 \%$ perceived the rainfall to be erratic in distribution while 5\% perceived an increase in rainfall amount.
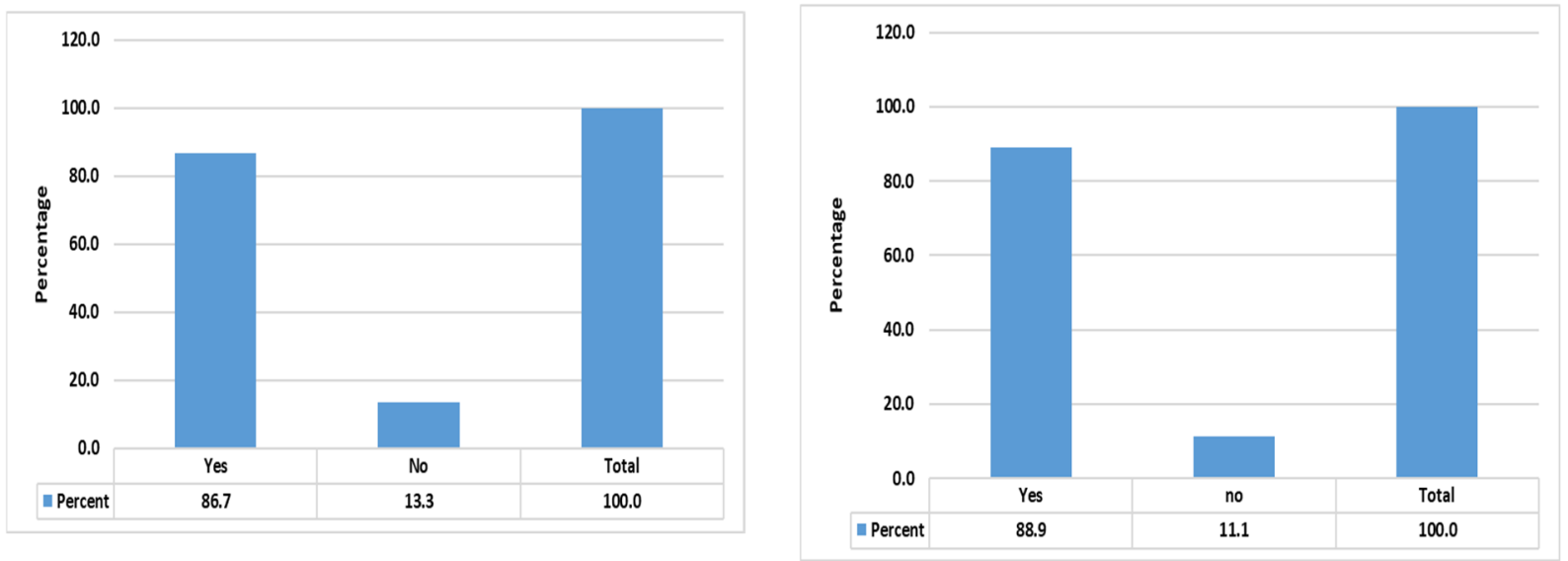

Figure 2. Household Perception on Changes in Temperature Figure 3. Perception on Changes in Rainfall

\subsection{Temperature Trend Analysis}

From the results, annual temperature showed an increasing pattern in the area under study within the last five decades (1961-2017). The estimation of the regression line reported an R-Square value of 0.478 for the average temperature. The implication is that, $48 \%$ of the change in average temperature is explained by the yearly temperature data over the period. This also established an average annual temperature trend equation of $\mathrm{y}=$ $0.0224 x+27$. 286. The positive slope exhibited in the trend line shows that the mean temperature has risen by $1.28{ }^{\circ} \mathrm{C}$ in the last 57 years at $1 \%$ significance level $(0.01)$ (Figure. 4 ). The mean temperature rose by $0.224{ }^{\circ} \mathrm{C}$ per decade, which makes it evident that temperature rose faster within the period under study (1961-2017).

The maximum and minimum temperature patterns were also estimated. The R-Square values were $57.6 \%$ and $21.9 \%$ for maximum and minimum temperatures respectively. The regression line for Maximum temperature was $\mathrm{Y}=0.0251 \mathrm{x}+32.838$ and $\mathrm{Y}=0.0197 \mathrm{x}+21.733$ for that of Minimum temperature. Both maximum and minimum temperature showed an increasing pattern with a $1.43{ }^{\circ} \mathrm{C}$ estimated increase in maximum temperature over the 57 year period and $0.25^{\circ} \mathrm{C}$ increase per decade. It also showed an estimated increase of $1.12^{\circ} \mathrm{C}$ in minimum temperatures over the 57-year period and $0.20^{\circ} \mathrm{C}$ per decade. Maximum temperature increased faster over the period at a significant level $(\mathrm{p}=0.006 \%)$ while the minimum temperature increased gradually.

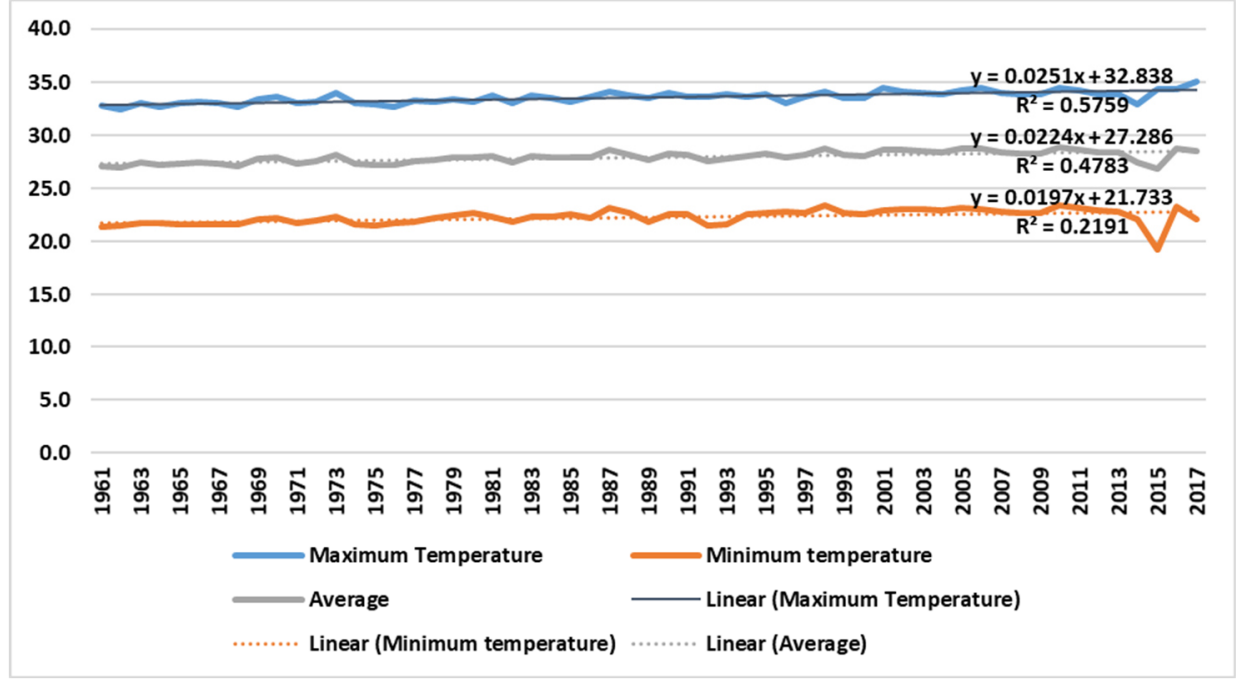

Figure 4 Maximum, Minimum and Average temperature trends 


\subsection{Rainfall Trend Analysis}

Meteorological data on rainfall was collected from the Ghana meteorological Agency (GMA) and analyzed to establish the rainfall variability for the fifty-seven years under study. The data showed that, the municipality recorded its highest rainfall amounts of 1,542.8mm in 1963 with a series of inconsistent rainfall patterns until 1986 where the lowest rainfall amount of $524 \mathrm{~mm}$ was recorded (Figure. 6).

The decline in rainfall agrees with the respondents believe that the rainfall pattern is very difficult to predict and erratic in nature. The municipality recorded an average yearly rainfall of $1,034 \mathrm{~mm}$ for the fifty-seven years under study which is not evenly distributed and not sufficient for crop cultivation. The analysis also showed that, total annual rainfall ranged from $524 \mathrm{~mm}$ to $1,543 \mathrm{~mm}$ with a yearly total mean of $1,034 \mathrm{~mm}$. The rainfall mostly occurs in Mid-June to Mid-September (Table 1). The standard deviation recorded for the months of August (82.2370) and September (62.5793) were the highest. Higher values of standard deviation depict higher uncertainty levels of rainfall (Table 4). Mean monthly precipitation was highest in the month of August (202.0 mm) and lowest in the month of February $(3.5 \mathrm{~mm}$ ) with rainfall at its peak between June and September (Figure 5).

The skewness and kurtosis computed indicated that, the mean rainfall did not follow a normal distribution (Figure 5). It was evident from the analysis that, the average yearly precipitation distribution is eventually reducing (Figure 6) whiles the long-term rainfall changes is seen to decline by $516.99 \mathrm{~mm}$ at a rate that is not significant (R2 $=0.066)$.

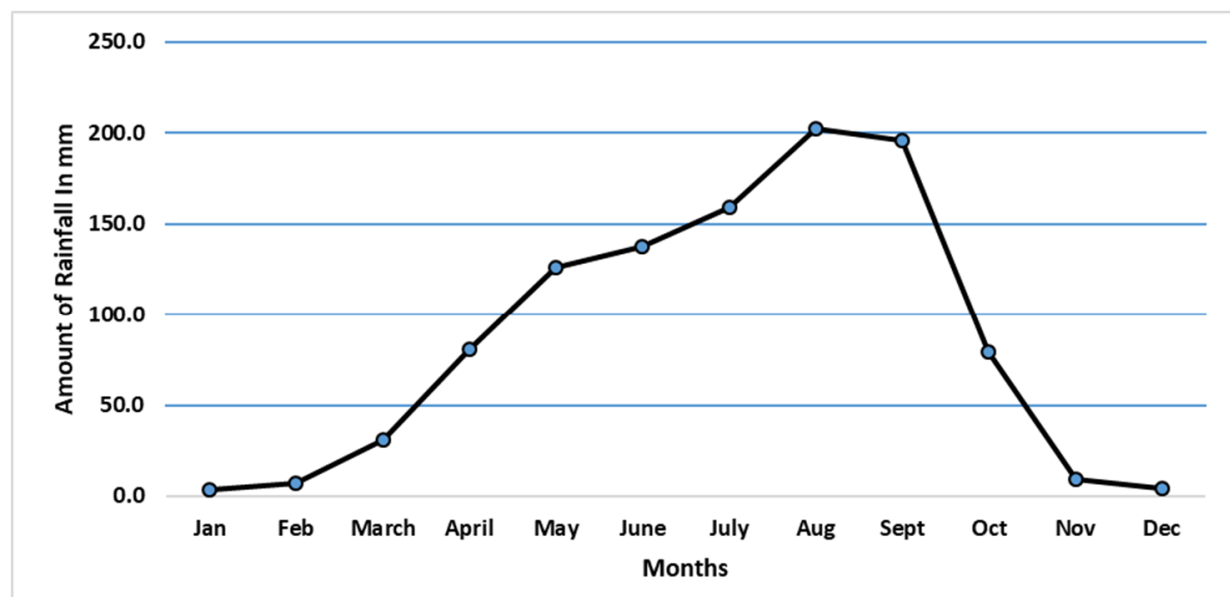

Figure 5. Long term monthly average rainfall distribution in Jirapa Municipality



Figure 6. Long term mean rainfall trend in the Jirapa Municipality 
Table 1. Average Monthly Rainfall over the Period

\begin{tabular}{llll}
\hline Month & Average & Standard Deviation & Skewness \\
\hline Jan & 3.5 & 12.4703 & 4.105108 \\
Feb & 7.3 & 17.8452 & 3.346728 \\
March & 31.0 & 27.8284 & 1.382161 \\
April & 80.4 & 42.0159 & 0.723765 \\
May & 125.8 & 40.6171 & 0.165247 \\
June & 137.6 & 58.2530 & 0.560588 \\
July & 158.9 & 60.8198 & 0.826237 \\
Aug & 202.0 & 82.2370 & 0.492452 \\
Sept & 195.7 & 62.5793 & 0.298153 \\
Oct & 79.4 & 51.8472 & 1.505855 \\
Nov & 9.0 & 13.7732 & 2.51135 \\
Dec & 4.1 & 11.0257 & 2.650725 \\
\hline
\end{tabular}

3.5 Meteorological drought analysis (1961-2017)

It is important to analyze the duration of drought, magnitude and severity because it provides important information for the development of good measures to mitigate climate change and the recommendation of adaptation strategies. Standardized precipitation index (SPI) was analyzed for the long-term drought trend. Negative SPI numbers depicts a drought event whiles positive SPI numbers shows an ends in drought occurrence. The rainfall within the study area can be seen as a variation of wet and dry years in a repeated trend (Figure. 7). The analysis revealed that, 33 years $(57.89 \%)$ were beneath the long-term mean annual rainfall amount whiles $23(40.35 \%)$ years recorded above-average. Positive SPI values were found to be more between 1962 and 1969 and also between 1995 and 2004. Negative SPI values were seen in succession from 1970 to 1976 and 1981 to 1992 . The 1986 precipitation quantity saw the least recorded in the duration under observation with SPI value -0.87 whiles the year 1968 recorded the highest amount of precipitation with an SPI value of 1.11.

The SPI result revealed a drought magnitude of 7. 89- and an intensity of 0.66 in the 12 years of duration which implies that agriculture lands are constantly exposed to severe drought situations in the Jirapa municipality. The droughts that occurred in 1986, 1970 and 1983 were the longest droughts recorded (12, 10 and 10 months, respectively) with a magnitude of 10.39, 6.94 and 6.54 respectively. It was evident that, the year 1990 was more serious with an intensity of 1.06. From the foregoing, the SPI in decadal years within the study area revealed that, the drought observed is mild as the values observed be are within the drought range of 0 to -0.90 .



Figure 7. Standardized precipitation index

\section{Discussion}

4.1 Demographic Characteristics and Households Perceptions of rainfall and temperature variations

Results from the socio-demographic characteristics of the respondents indicate that, majority of the household's heads were males. This result is consistent with (GSS, 2014), who reported that, male headed households account 
for the majority in rural areas within the upper west region of Ghana. Most of the household heads were 50 years and above, which suggest that their opinion on climate change is based on long years of exposure and experience. It was noted by Deressa (2011) that, older household heads have more experience interms of exposure to climate variability and makes them more willing to accept and adapt mitigation measures. The average household size was estimated to be 8 . This is greater than the mean household size of 4.0 in Ghana and also above the mean household size of 6.5 in the Upper West Region (Schneider et al., 2014). This implies that climate change will further worsen the incidence of food insecurity within the district as more food is required to feed the growing household population as indicated by (Haq and Ahmed, 2016). A large proportion of the sampled households (74.4\%) had no formal education. This result is consistent with the Ghana statistical services report, which indicated that only $21 \%$ of household heads in the Upper West region are literate. It was indicated by Kabir et al. (2016) in their study that education influences the level of awareness to climate change related issues with household heads who possess higher education level been more aware than those with lower education levels.

It was generally agreed by respondents that the climate is consistently changing and getting intensified over time. Generally, majority of the households have perceived a rising pattern in temperature with a reducing trend in rainfall which is erratic in distribution. This reflects the revelation that, farmers perceived a reduction in precipitation and a rise in temperature within the Bibani-Anhwiaso Bekwai district in Ghana (Armah et al., 2019; Assan et al., 2018). Lawson et al. (2020) also observed that, respondents' perceived a reducing trend in rainfall. The result from the study of Demeke et al. (2011) revealed that respondents have witnessed an increasing trend in temperature and serious dry seasons with rainfall becoming more erratic in distribution over the years within the study area. This has resulted in more droughts and floods within the same seasons. These findings also support the findings of Appiah et al. (2018) who mentioned that erratic precipitation trend, rise in temperature and frequent floods were signs of climate alterations and climate change as observed by farmers within the study communities (Dickinson et al., 2016). Mangnus and Westen (2018) mentioned that a greater percentage of farmers perceived an eratic distribution in rainfall and rainfall patterns have become unpredictable.

\subsection{Analysis of Temperature and Rainfall Variability with Data from Ghana Meteorological Authority}

The analyzed meteorological records showed that there has been a rising pattern in annual temperature within the study area over past five decades (1961-2017). On the average, temperature has increased by $1.28^{\circ} \mathrm{C}$ in the last 57 years. Lawson et al. (2020) showed that average yearly temperature has risen in the last decade (1990-2009) and it was estimated that, temperature will increase from $0.4^{\circ} \mathrm{C}$ to $1^{\circ} \mathrm{C}$ in the upcoming two decades $(2010-2029)$ in the Upper West Region. The result also showed that, both maximum and minimum temperature has an increasing trend with a $1.43{ }^{\circ} \mathrm{C}$ estimated increase in maximum temperature over the 57 -year period and $0.25^{\circ} \mathrm{C}$ increase per decade. Armah et al. (2019) also observed an increase in maximum and minimum temperatures within the study area (Rahman and sekyere, 2017). Amankwah (2019) showed that, a significant increase in temperature across the north of Ghana was recorded and a decline in rainfall is more visible in the Upper West Region (UWR), Northern Region (NR) and Upper East Region (UER) respectively. Severe temperatures recorded within the study area can affect soil quality during droughts that occur at the start of the season which can negatively affect crop establishment, farmer's livelihoods and food security. The results also conforms with other studies (Frimpong et al., 2014; Abam et al., 2018; Asamoah and Meansah, 2020)

The municipality has also witnessed a single rainfall pattern. The records indicate that, the average annual rainfall spread is eventually reducing with a decrease in long-term rainfall. The study also conforms to the study of (Owusu and Weylen, 2009; Baidu, 2016). This finding is also in support of (Issahaku et al., 2016; Logah et al., 2013). The study however, is in contrast with Asamoah and Mensah (2020) who established a little increase in precipitation distribution within the Bawku area. Accordingly, Fosu (2013) indicated that, it is difficult to predict precipitation patterns in Ghana as years of drought are being followed closely by years of flooding.

\subsection{Meteorological drought analysis (1961-2017)}

Rainfall is by far the primary indicator of reduced water supply and hence meteorological drought (Elagib, 2013). Drought can be seen as the shortage in rainfall which can affect livelihood resources and water security. The SPI result indicates that the Jirapa municipal has been exposed to a 33-year period of drought within five decades which have severe implications on agricultural lands and crop productivity. Even though the SPI showed a mild drought recorded within the years under study, there were more dry spells which has great impact on crop production. The study is also in acceptance with Schipper (2007) who mentioned that mild droughts can have greater implications than bigger droughts. Recurrent lost in crop can be attributed to successive droughts which has resulted in food unavailability in the area in recent times. Elagib (2013) also observed that, most of the drought cases were mild and only one case was severe in the study area. Forty-six $(92 \%)$ of the respondents interviewed, had witnessed drought conditions before. This agrees with an early research conducted by Nti (2012) revealed that households see droughts to be normal within the municipal because of the nature of the climate. 


\subsection{Implications For Food Security}

Food security is characterized by food Stability, Availability, Access and Utilization (FAO, 2012; Ericksen, 2008). A person can only be declared food secured when all these four areas have been achieved, Henceforth, these four dimensions are discussed below in the context of climatic factors such as temperature and rainfall.

\subsubsection{Food Availability}

Food availability is when food is present through and available through the stages of production, physical distribution and exchange of food (Connolly and Smit, 2015). From the meteorological analysis, temperature within the municipality has shown a significant rising pattern with a decreasing rainfall trend. The rising trend in temperature has a negative impact on agriculture most importantly crop productivity which is the major livelihood source for households within the district. Increasing temperature comes along with a rise in the rate of evapotranspiration and a reduction in surface and underground water, thereby making water unavailable for crop productivity and henceforth causing a reduction in crop yield and crop failure (IPCC, 2018). With 98.1\% of the households indicating that their major source of livelihood is dependent on crop production, a reduction in yield will reduce food availability which will negatively affect household food security. As a way to diversify their source of income and food availability, majority of the households confirmed that they rear livestock's. Unfortunately, $90.6 \%$ of the households have lost their livestock over the years with which $81.1 \%$ attributed it to incidence of pest and diseases and $10.6 \%$ to poor pasture. This has reduced the availability of food within the district and increased food insecurity among households. Addisu et al. (2016) made it clear that the intensity and spread of animal diseases can be attributed to climate change. Increasing temperatures also slows the growth and production trend of animals (Nuamah and Botcway, 2019; Thornton et al., 2014). Farmers within the district rely on dams for irrigation during dry season gardening as a means to supplement household food supply. The dams have not been spared from droughts as the amounts of rainfall keep on reducing over the years which has made food unavailable and has worsened food insecurity within the municipality. It was noted by Li et al. (2019) that, extreme dry conditions resulted in a significant destruction, which minimized maize yield (Asamoah and Mensah, 2020).

The study revealed that August and September were the months with greater standard deviations with the months of August and September seeing the highest amount of mean monthly rainfall. Rainfall intensity is high within these months. It was mentioned that the rise in rainfall intensity within these months has increased water levels within the Black and White Volta Rivers (which passes through the study communities) resulting in flooding and caused destructed productive farmlands, putting lives and properties at risk and further increasing food insecurity levels of households.

\subsubsection{Food Stability and food Assess}

Variability in temperature, rainfall and persistent drought observed within the study area poses a threat to food stability component of food security by changing the cropping cycles and reducing crop yields. Jibrillah et al. (2018) mentioned that variability in climatic factors have contributed to the diminishing of agricultural lands and grasslands whiles intensifying the availability of water with an overall negative effect on livelihood, food stability and food insecurity. It was also noted by Wheeler and Broun, 2013 that, the consistent occurrence of climate related hazards would lead to an increase in worldwide food prices, with an indirect impact on the overall stability of food systems.

The accessibility component of food security depends on the ability of households to obtain food from purchases, gathering, current production, or stocks (Hartel and Rosch, 2013; Reidsman et al., 2010). According to FAO (2012), the more people are exposed to climate change events, the more their accessibility to food is reduced and their food security is threatened. Renzaho and Mellor (2010) noted that access to food, is determined by income level, access to resources, the physical and social environment, the cost of food, and government and trade policies. Households within the study area generally buy food to complement their food reserves which agrees to the study of (Issahaku et al., 2016). Food Insecurity in Upper West last for about five months for the maize crop, which is the major staple crop cultivated among rural households within the Jirapa municipality (Quaye, 2008). During these periods, the price of both maize meal and maize grains have risen and most households that have less or no maize available will have to purchase to supplement their consumption. Besides this, income in the area, which is a critical component of access, is centered on maize production. Therefore, the reduction in maize yield, due to the increasing trend in temperature, reduction in rainfall and persistence of droughts, has negatively affected household income and food security as the households do not have enough maize stock that can be sold to supplement income. This situation confirms literature by (Schmidhuber and Tubiello, 2007) who mentioned that food security is not only about the availability of food but it is also driven towards the financial and non-financial resources available to people to enable them access food and food sources.

4.4.4 Food Utilization

Food utilization is the aspect of food security that is greatly affected the most by climate change (Zewdie, 2014). Utilization depicts the relevant nutritional composition of food and how the body can potentially utilize it efficiently (FAO, 2012; Ericksen, 2008). Majority of rural poor households attain micronutrients from the 
consumption of crops and other plants (Issahaku et al., 2016). Climate change has the ability of reducing the yields of major crops that are important sources of micronutrients, change the nutritional composition of crops and can also influence decisions to grow. Households within the study communities employ various strategies to cope with food shortages in order to feed their families. They typically decrease the quantity of meals available each day, decreases the sizes of food and consume less nutritious food with varying nutritional qualities which has affected food utilization and increased the threats of food security.

Historical climatic data from the study area revealed that the average temperature has past by $1.28{ }^{\circ} \mathrm{C}$ in the last 57 years. High temperatures has led to the prominence of pest and diseases with severe health implications on individuals within the households. Once their health is challenged, the ability to utilize food properly decreases (Issahaku et al., 2016). The analyzed meteorological data showed that, the months of July, August and September recorded the highest standard deviation with intense rainfalls which has led to flooding within the area. Flooding has resulted in the stagnation of water in the communities which has increased the predominance of vector-borne and water-borne diseases such as malaria and cholera respectively. These diseases pose severe health risk to people and affect food utilize among individuals. (Yamane, 1967). Household food security is greatly threatened, because individuals cannot utilize food adequately because of the reduction in nutritional importance of food and food safety (Boutin and Smit, 2016; Islam and Wong, 2017). Climate parameters such as temperature, rainfall variability and extreme droughts has affected the quality of maize grain which is the major staple food source within the municipality. Less healthy food gradually affects individual's physiology which reduces their food intake and ability to obtain the necessary nutrients from food consumed (Tirado et a., 2010) which is of great threat to food security (Ziervogel et al., 2014). Vegetable cultivation is the major source of nutrients and income to households within the dry season in the municipal. Unfortunately, productivity has been affected adversely by droughts and temperature variability. The drying out of dams as a result of temperature rise has drastically reduced the availability of nutritious vegetables and decreased access to and consumption of nutrient reach vegetables which had affected food utilization and thereby promoting food insecurity (Myers et al., 2017).

\section{Conclusion}

The varying climate and intensifying food insecurity have brought untold hardships on the people of Jirapa municipality, Ghana. The perception of rural that, the climate is increasingly becoming more variable as seen from the Meteorological analysis presents a positive outlook to the rural household of the municipality. The meteorological trend analysis revealed a significant rise in mean temperature with a decline in mean rainfall. The results showed that, variations in climatic factors has reduced the food security and negative affected livelihoods of households which has increased the poverty level of households. This is so because erratic rainfall trends and severe temperatures caused a reduction in crop yields within the study area. The study showed that, climate change is a reality in the Jirapa municipality and it has a serious implication on food security via its impacts on the four dimensions of food security. Hence it is necessary to increase education and research to increase knowledge, particularly of rural farm household to improve their adaptation to changes in order to increase food security. Increasing the capacity of rural farm households through interventions such as adaptation strategies and financial and risk support will help improve resilience climate change impacts. Government and stakeholder participation in the maintenance and protection of natural resources will help lessen the climate change impacts and encourage communities adopt strategies that would mitigate the effects of climate change.

\section{References}

Abbam, T., Johnson, F. A., Dash, J., and Padmadas, S. S. (2018). Spatiotemporal variations in rainfall and temperature in Ghana over the twentieth century, 1900-2014. Earth and Space Science. 5, 120-132. https://doi.org/10.1002/2017EA000327.

Addisu, L., Olutayo, O. A., Suleiman, H., and Rao, P. (2016). Assessing Climate Change Impacts in the Lake Tana Sub-Basin, Ethiopia Using Livelihood Vulnerability Approach. Journal of Earth Science \& Climatic Change. 7(9): 1-10. DOI: https://doi.org/10.4172/2157-7617.1000368.

Akudugu, M. A., Dittoh, S., and Mahama, E. S. (2012). The implications of climate change on food security and rural livelihoods: Experiences from Northern Ghana. Journal of Environment and Earth Science, 2(3), 2129.

Amankwah, E. (2019). Impact of Climate variability and change on agricultural productivity in the three northern regions of Ghana. American Journal of Environmental Science \& Technology. 3:30-41.

Appiah, D.O., Akondoh, A.C.K., Tabiri, R.K., and Donkor, A.A. (2018). Smallholder farmers' insight on climate change in Gural Gonar \& $\&$ Agriculture. 4:1,1436211:https://doi.org/10.1080/23311932.2018.1436211.

Armah, A.A., Christina, A.N., and Gloria, E.O. (2019). Climate change and food and nutrition security in the Bibiani-Anhwiaso Bekwai district in the Western Region of Ghana. Cogent Environmental Science. 5:1, 1681613 
Asamoah, Y., and Mensah, K.A. (2020). Temporal Description of Annual Temperature and Rainfall in the Bawku Area of Ghana. Hindawi Advances in Meteorology. Vol. 64, no. 5.

Assan, E., Suvedi, M., Schmitt Olabisi, L., and Allen, A. (2018). Coping with and Adapting to Climate Change: A Gender Perspective from Smallholder Farming in Ghana. Environments. (5) 86.

Baidu, M. (2016). Assessment of long-term spatio-temporal rainfallvariability over Ghana using wavelength analysis. Submitted to the Department of Physics, Kwame Nkrumah University of Science and Technology, Kumasi, Ghana.

Boutin, L.C., and Smit, B. (2016). Climate change, food security, and livelihoods in sub-Saharan Africa. Reg Environ Change. 16:385-399. DOI 10.1007/s10113-015-0761-x conori.

Connolly, B.L., and Smit, B. (2015). Climate change, food security, and livelihoods in sub-Saharan Africa. Reg Environ Change. 16:385-399. DOI 10.1007/s10113-015-0761-x.

Demeke, A.B., Keil, A., and Zeller, M. (2011). Using panel data to estimate the effect of rainfall shocks on smallholder's food security and vulnerability in rural Ethiopia. Climatic Change. volume 108, pages 185-206.

Deressa, T., Hassan, M., and Ringler, C. (2011). Perception of and adaptation to climate change by farmers in the Nile basin of Ethiopia. J Agric Sci. 149:23-31, doi: 10.1017/S0021859610000687.

Dickinson, L.K., Monaghan, A.J., Rivera, I.J., Hu, L., Kanyomse, E., Alirigia, R., Adoctor, J., Kaspar, R.E., and Wiedinmyer, C. (2016). Changing weather and climate in Northern Ghana: comparison of local perceptions with meteorological and land cover data. Reg Environ Change. DOI 10.1007/s10113-016-1082-4.

Elagib, N.A. (2013). Meteoroligical Drought and Crop Yield in Sub-Saharan Sudan. International Journal of Water Resources and Arid Environments. 2(3): 164-171.

Ericksen, P. J. (2008). Conceptualizing food systems for global environmental change research. Global Environmental Change. 18(1), 234-245. doi:10.1016/j. gloenvcha.2007.09.002.

Evironmental Protection Agency. First National Communication to UNFCCC. 2000. Epa.gov.gh, (accessed on 9 September 2019).

FAO. (2012). Food supply. Available at http://faostat.fao.org/. (Accessed 10 July, 2017).

Fosu, B. Y. (2013). Modelling the Impact of Climate Change on Maize (Zea mays L.) Yield under Rainfed Condition in Sub-humid Ghana. UNU-INRA working Paper No 1.

Frimpong, K., Oosthuizen, J., and Van, E.J. (2014). Recent trends in temperature and relative humidity in Bawku East, Northern Ghana. Journal of Geography and Geology. vol. 6, no. 2, pp. 69-81.

Ghana Statistical Service, (2014). Statistics for Development and Progress; National Accounts Statistics. Gross Domestic Product. Available online: http://www.statsghana.gov.gh/docfiles/GDP.PDF, (accessed on 29 July 2020).

Haq, S.M.A., and Ahmed, K.J. (2016). Does the perception of climate change vary with the socio demographic dimension? A study on Vulnerable Population in Bangladesh. Natura Hazards. 85, 1759-1785 (2017). http://DOI.ORG/10.1007/s11069-016-2664-7.

Hertel, T. W.,f and Rosch, S. D. (2010). Climate change, agri- culture, and poverty. Applied Economic Perspectives and Policy. 32(3), 355-385. doi:10.1093/aepp/ppq016

International Fund for Agriculture Development. Adaptation for Smallholder Agriculture Programme. (2012). http;//www.ifad.org (accessed on 19 June, 2018).

IPCC. (2013). Detection and Attribution of Climate Change: from Global to Regional. Fifth Assessment Report, Working Group I, Chapter 10. Cambridge, United Kingdom and New York, NY, USA.

IPCC. (2018). IPCC Special Report on the Impacts of Global Warming of $1.5^{\circ} \mathrm{C}-$ Summary for Policy Makers. Incheon, Korea.

Islam, M.D.S., and Wong, T.A. (2017). Climate Change and Food In/Security. MDPI Environment. 4, 38; doi:10.3390/environments.

Issahaku, A.R., Campion, B.B., and Edziyie, R. (2016). Rainfall and temperature changes and variability in Upper East region of Ghana. Earth Sp. Sci. 3, 284-294.

Jibrillah, A. M., Choy, I. K., and Jaafar, M. (2018). Climate change manifestations and impacts in the Sokoto close-settled zone, Northwestern Nigeria. Akademika, 88(2), 21-34. doi:10.17576/akad-2018-8802-02.

Kabir, M.D.I., Rahman, M.D.B., Smith, W., Lusha, M.A.R., Azim, S., and Milton, A.B. (2016). Knowledge and perception about climate change and human health: findings from a baseline survey among vulnerable communities in Bangladesh. BMC Public Health. 16:266.

Lawson, E.T., Alare, S.R., Rauf, A., Salifu, Z., and Hall, T.M. (2020). Dealing with climate change in semi-arid Ghana: understanding intersectional perceptions and adaptation strategies of women farmers. GeoJournal. 85:439-452. https://doi.org/10.1007/s10708-019-09974-4.

Li., Y.; Guan, K., Schnitkey, D.G., Delucia, E., and Peng, B. (2019). Excessive rainfall leads to maize yield loss of a comparable magnitude to extreme drought in the United States. Global change biology. DOI: 10.1111.

Logah, F.Y., Obuobie, E., Ofori, D., and Yeboah, K.K. (2013). Analysis of Rainfall Variability in Ghana. International Journal of Latest Research In Engineering and Computing. Volume 1, Issue 1: Page No.1-8. 
Mangnus, E., and Westen, A.C.M. (2018). Roaming through the Maze of Maize in Northern Ghana. A Systems Approach to Explore the Long-Term Effects of a Food Security Intervention. Sustainability. 10, 3605.

McKee, T.B., Doesken, N.J., and Kleist, J. (1993). The relationship of drought frequency and duration to time scales. Proceedings of the 8th conference on applied climatology. Colorado State University, Anaheim, California, pp 1-6.

Ministry of Food and Agriculture. (2016). Agriculture in Ghana Facts and Figures. Mofa.gh.gov (accessed on 3 April, 2020).

Myers, S.S., Smith, R.K., Guth, S., Golden, C.D., Vaitla, B., Mueller, N.D., Dangour, A.D., and Huybers, P. (2017). Climate Change and Global Food Systems: Potential Impacts on Food Security and Undernutrition. Annu. Rev. Public Health. 38:259-77.

Naab, F.Z., Abubakari, Z., and Ahmed, A. (2019). The role of climate services in agricultural productivity in Ghana: The perspectives of farmers and institutions. Climate Services. 1324-32. https://doi.org/10.1016/j.cliser.2019.01.007

Newman, D. A. (20140. Missing data: Five practical guidelines. Organizational Research Methods, 17(4), 372411.

Nti, F. K. (2012). Climate change vulnerability and coping mechanisms among farming communities in Northern Ghana: Master Thesis: http://krex.kstate.edu/dspace/bitstream/handle/2097/.../FrankNti2012rev.pdf?; (accessed November, 2018).

Nuamah, P.A., and Botchway, E. (2019). Understanding climate variability and change: analysis of temperature and rainfall across agroecological zones in Ghana. Heliyon. 5 e02654.

Owusu, K., and Weylen, P. (2009). Trends in spatio-temporal vari-ability in annual rainfall in Ghana (1951-2000). Weather. vol. 64, no. 5, pp. 115-120, 2009.

Peprah, K. (2014). Rainfall and Temperature Correlation with Crop Yield: The Case of Asunafo Forest, Ghana. International Journal of Science and Research. Volume 2 issue 5. ISSN (Online): 2319-7064.

Quaye, W. (2008). Food security situation in northern Ghana, coping strategies and related constraints. African Journal of Agricultural Research. Vol.3, No. 5, pp. 334-342.

Rahman, A.I., and Sekyere, E.O. (2017). Climate variability and sustainable food production: Insights from northeastern Ghana. Ghana Journal of Geography. Vol. 9(2), Pages 67-89.

Reidsma, P., Ewert, F., Lansink, A. O., Leemans, R. (2010). Adaptation to climate change and climate variability in European agriculture: The importance of farm level responses. European Journal of Agronomy. 32, 91102. doi:10.1016/j.eja.2009.06.003

Renzaho, A.M., and Mellor, D. (2010). Food security measurement in cultural pluralism: missing the point or conceptual misunderstanding? Nutrition. 26(1):1-9. doi:10.1016/j.nut.2009.05.001

Schipper, L. (2007). Climate change and development: exploring the linkages. Tyndall Centre working paper 107. Norwich: Tyndall Centre.

Schmidhuber, J., and Tubiello, F. N. (2007). Global food security under climate change. Proceedings of the National Academy of Sciences of the United States of America. 104(50), 19703-19708. doi:10.1073/ pnas.0701976104

Schneider, U., Becker, A., Finger, P., Meyer, C., Ziese, M., and Rudolf, B. (2014). GPCC's new land surface precipitation climatology based on quality-controlled in situ data and its role in quantifying the global water cycle. Theoretical and Applied Climatology, 115(1-2), 15-40. https://doi.org/10.1007/s00704-013-0860-x.

Subaar, C., Apori, N., Fletcher, J.J., Galyuon, R., Edusei, G., and Adayira, W.W. (2018). Time Series Analysis for Prediction of Meteorological Data from Wa, Upper West Region of Ghana. Climatol Weather Forecasting, 6:3 DOI: 10.4172/2332-2594.1000237.

Thornton, P. K., Ericksen, P. J., Herrero, M., and Challinor, A. J. (2014). Climate variability and vulnerability to climate change: a review. Glob. Chang. Biol. 20, 3313-3328.

Tirado, M. C., Clarke, R., Jaykus, L. A., McQuatters, A., and Frank, J. M. (2010). Climate change and food safety: A review. Food Research International. 43(7), 1745-1765. doi:10.1016/j.foodres.2010.07.003.

United Nations Framework Convention on Climate Change. (2009). Climate Change: Impacts, Vulnerabilities and Adaptation in Developing Countries. www.unfccc.int/resource/docs/publications/impacts.pdf (accessed on 28 April 2017).

United Nations Framework Convention on Climate Change. (2011). Fact Sheet: Climate Change Science - the Status of Climate Change Science Today. www.unfcc.int (Accessed on 15 June, 2020).

Wheeler, T., and von Braun, J. (2013). Climate change impacts on global food security. Science. 3,103-127

World Food Programme. (2009). Comprehensive Food Security \& Vulnerability Analysis (CFSVA) Ghana. VAM Food Security Analysis. http.//www.wfp.org, (accessed on 4 August, 2020).

Yamane, T. (1967). Statistics, An Introductory Analysis. 2nd Ed. New York.

Zewdie, A. (2014) Impacts of Climate Change on Food Security: A Literature Review in Sub Saharan Africa. $J$ Earth Sci Clim Change. 5: 225. doi:10.4172/2157-7617.1000225. 
Ziervogel, G., Nyong, A., Osman, B., Conde, C., Cortes, S., and Downing, T. (2014). Climate Variability and Change: Implications for Household Food Security. AIACC Working Papers. 2014, 241137955. 